show the Martian features in spring (southern hemisphere), and later at the beginning of summer, and it is seen that at the later epoch the markings were more numerous and better defined.

PERRINE's COMET, IgOgb.-From the recent observations (August-October) of Perrine's periodical comet Dr. Kobold has calculated a set of elements, which he gives in No. 4368 of the "Astronomische" Nachrichten (p. 405, November IO); this gives the perihelion passage as 1909 October 31.865 (M.T. Berlin). An ephemeris is also published showing that the comet is apparently travelling, nearly due south, through Gemini, as shown by the following positions:-November is, 7 h. $3.8 \mathrm{~m}$., $+17^{\circ}{ }_{46} 6.8^{\prime}$; November 30 , $7 \mathrm{~h}$. I I. $9 \mathrm{~m} .,+5^{\circ} 45 \cdot 5^{\prime}$. On November I9 the comet will be some minutes west of $\lambda$ Geminorum, and of about magnitude $12 \cdot 3$.

The Liverfool Astronomical Society.-The annual report of the Liverpool Astronomical Society shows that its activity and membership are being well maintained. In the presidential address $\mathrm{Mr}$. W. E. Plummer gives an interesting paper on satellites, and other notes, by $\mathrm{Mr}$. Thorp and Father Cortie respectively, deal with diffraction gratings and sun-spot spectra. There is also a paper on Morehouse's comet, illustrated by a frontispiece reproducing photographs taken by four of the society's members.

The Parallax of the Double Star $\Sigma$ 2398. - In these columns on September 16 we directed attention to Dr. Bohlin's re-determination of the parallax of the double star $\Sigma$, from which it followed that this star, with a parallax of $0.484^{\prime \prime}$, is the nearest to us in the northern hemisphere.

Since Dr. Bohlin's publication several observers have directed attention to the discordance of the above value from several previously determined, Prof. Schlesinger pointing out (Astronomische Nachrichten, No. 4365, p. 359 ) that it is probably. $0.15^{\prime \prime}$ too high.

Dr. Bohlin now states (ibid.) that an error crept into his calculations, and that, on correcting this, the parallax derived from his observations is $+0.25 \mathrm{I}^{\prime \prime}$; there are, at least, eight or nine stars in the northern hemisphere for which greater parallaxes than this have been fourd.

\section{THE MEASUREMENT OF SOLAR RADIATION ${ }^{1}$}

IN the long memoir referred to below Dr. Bemporad discusses a variety of problems relating to the measurement of solar radiation, a subject to which he has made previous contributions. The material employed consists mainly of observations made with pyrheliometers of the now common Angström pattern at the peak of Teneriffe during five days in June and July, 1896. Prof. Angström and an assistant observed at two different heights, the two stations simultaneously occupied being one at a level of $325^{2}$ metres; the other at one or other of the three levels 3683,2125 , and 360 metres.

On an average day there were about sixteen observations at each of the two stations occupied. The observations were scattered over the day, the zenith distances of the sun usually ranging from a little more than $5^{\circ}$ to between $80^{\circ}$ and $90^{\circ}$. The pyrheliometer reading on reduction gives $q$, the heat received in unit time by a unit of surface placed orthogonally to the sun's rays. As the sun's zenith distance alters, there is at any station a change in the length of the path of the sun's rays through the atmosphere. The longer the path, the greater the loss by absorption, and the first problem considered by Bemporad is which of several formulæ, due to Crova, Bartoli, Pouillet, and himself, best represents the variation of $q$ with zenith distance. The formulæ all contain a quantity $e$ defined as the "mass" of air traversed by the rays (for this purpose a ray may be regarded as a tube of unit section), unity representing the value of $e$ for a vertical ray. The author refers to a previous memoir in which he has tabulated $e$ as a function of $z$, the zenith distance, at sea-level. Treating the morning and afternoon observa-

1 "L'Assorbimentn selettivo della Radiazione solare nell' Atmosfera terrestre e la sua variazione coll' altezza.". By Dr. A. Bemporad. Pp. Irr.
From Reale Accademia dei T.jncei, anno cecv., tgo8. (Roma: Tipografia From Reale Accatemia dei T.incei, an
della R. Accademia dei Lincei, roo8.)

No. 209o, VOL. 82] tions of each day at each station separately, he calculates the best values for the constants $q_{0}$ and $m$ in a formula of Crova's type $q=q_{0}(\mathrm{I}+\boldsymbol{e})^{-m}$. The average difference between the individual. observed and calculated values is usually well under I per cent. The author seems, however, to prefer a three-constant formula of the type $\log q=a-b e^{n}$, and makes numerous comparisons with formulæe of this type.

If we neglect the earth's curvature and the small variation in $z$ at different levels due to refraction, and regard the atmosphere as formed of "layers" bounded by parallel planes, an increase of $z$ increases the length of path in ail layers in the same proportion. Thus the formula involving $e$ do not really assume that the absorption in travelling through a given "mass" of air is the same at ail levels. With the view of ascertaining the variation in absorption with height, the author proceeds to calculate the "mass" of air traversed by rays, having different values of $z$, in passing from the level of one of Ängström's stations to another. This is got by a slight modification of the difference between the air "masses" from sea-level up to each of the two heights, as given in a table previously published by the author. One assumption in the process which rather invites criticism-though there is no obvious means of avoiding. it in the absence of direct observations-is that the temperature gradient was the same at all levels and deducible from the observations at the two stations. Having found $M$, the "mass" of air traversed between the levels of the two stations, the author assumes that the simultaneous values $q$ and $q^{\prime}$ of $q$ at the two stations are connected by a formula of the type $\log \left(q^{\prime} / q\right)=c \mathrm{M}$, where $c$ is the mean absorption per unit mass of air for the layer between the two heights. Angström's four stations supply, of course, three layers, though the data for the three refer really to different days. Thus three values of $c$-answering to three different layers or to three different mean heights in the atmosphere-are obtained for a series of different values of $z$. One noteworthy feature is the tendency of $c$, for a given value of $z$, to be greater in the afternoon than in the forenoon. The author finds $c$ to diminish notably with the altitude of the layer, and he concludes in favour of the empirical law that the absorption at different heights varies as the fourth power of the density of the air. This conclusion was derived primarily from : Angström's observations alone, but the author tests it by reference to results obtained by Millochau at Mont Blanc, Langley at Mount Whitney, and Rizzo at Rocciamelone. On p. 97 he considers the relationship of his formula to the law of variation with height usually proposed for aqueous vapour.

In an earlier paper: the author had tabulated the value $M$ of the "mass" of air traversed by a ray between sea-level and heights varying up to 5000 metres for different values of $z$. His calculations assumed the temperature gradient $\beta$ to be $6 \cdot 2^{\circ} \mathrm{C}$. per $\mathrm{km}$. In an appendix to the present memoir he gives the corrections to be applied to the previous table when the value of $\beta$ is not $6 \cdot 2^{\circ}$, but $6^{\circ}, 5^{\circ} \ldots 0^{\circ}$. By a curious oversight the table for $\beta=2^{\circ}$ is printed twice over on p. I03, that for $\beta=\mathrm{I}^{\circ}$ being omitted.

The author refers in various places to the fact that the absorption by the atmosphere is selective, the presence of aqueous vapour in the lower strata being specially important; but Angström's observations in 1896 dealt only with the total radiation. He also recognises that the presence of a mountain may disturb the atmospheric conditions in its immediate neighbourhood. He apparently ascribes to this -and with good reason-certain anomalous results derived from Angström's two highest stations, according to which the absorption in the intervening layer was at times negative. One cannot but entertain some doubt whether the subject is yet quite ripe for mathematical calculations of so elaborate a type as the author's. There would certainly. have been a much more suitable field for their application if he had had at his disposal absolutely synchronous data from seven or eight stations-preferably in the free atmosphere--at heights differing by regular intervals of, say, 500 metres, results being obtained, not merely for the total radiation, but for the portions passed by a series of filters after the method recently pronosed by Ångström.
C. Chree. 